\title{
Impact of Teaching Practice on Pre-Service Teachers' Pedagogical Competencies in Tanzania
}

\author{
Jimmy Ezekiel Kihwele ${ }^{1,2^{*}}$, Raiza Mtandi ${ }^{2}$ \\ ${ }^{1}$ Centre for Teacher Education Research, Beijing Normal University, China \\ ${ }^{2}$ Department of Education, Mzumbe University, Tanzania \\ "Corresponding author:jikihwele@mzumbe.ac.tz
}

\begin{abstract}
Teaching practice is an integral part in preparing pre-service teachers and initiates them to the actual teaching environments. TP has been frequently interrupted hence raising a concern about its contribution on improving pedagogical competencies. This study sought to understand the contribution of teaching practice on developing pre-service teachers' pedagogical competencies. The study adopted case study design through the mixed approach that involved a total of 81 respondents from Mzumbe University in Tanzania. Respondents were picked from their teaching practice stations to fill in the questionnaires with 36 items. Participants consent was obtained before taking part in responding to questionnaires. The findings show that, pre-service teachers perceive TP as a crucial part of teacher education as it helps to consolidate pedagogical skills. Again, TP contributed to develop pre-service teachers' pedagogical competencies through merging theoretical understanding and actual practices as well as how to select, prepare and use teaching and learning materials and aids. Further, findings show challenges like inadequacy of single assessment, poor mentor-novice teacher relationship and interruptions that reduced the actual teaching time. TP requires some modifications including improved relationship between pre-service teachers and host teachers, to increase the TP duration to compensate lost time due to interruptions and pre-service teachers need to be assessed more than once. It is recommended that time for TP should be reviewed in the universities curricula for pre-service teachers to have practical experience and get mentorship from experienced teachers. In this way, TP will become an apprenticeship with great impact to the teaching profession.
\end{abstract}

Key words: Teaching practice, pre-service teachers, pedagogical competencies, Tanzania

\section{Introduction}

Teaching Practice (TP) is an integral part in teacher education to prepare pre-service teachers and initiate them to the actual teaching environments (Mangope, Otukile-Mongwaketse, Dinama, \& Kuyini, 2018; Mannathoko, 2013). According to Manasia, lanos and Chicioreanu (2020), there are four domains that pre-service teachers are expected to improve during TP; (i) planning and preparation, (ii) classroom environment, (iii) instruction and (iv) professional responsibility. Although TP has been conducted as a requirement for awarding or certification of educational programs, its important role is to enable teachers in training to apply theoretical knowledge developed during the training into practice in real school settings (Aglazor, 2017). According to Komba and Kira (2013), TP is regarded as a preparation of pre-service teachers for maximum practical and professional training. Preservice teachers learn and gain experience through participation and observation under the mentorship of experienced teachers in the host school. The development of the professional skills and competencies through exposing pre-service teachers to actual environment helps to prepare the pre-service teachers for effective teaching. In TP, the pre-service teachers are given an opportunity to merge theories and actual teaching under the supervision of a mentor (Nakpodia, 2011). An effective TP is crucial in influencing pre-service teachers' proficiency in their professional practices. 
This is because teachers in schools seem to be struggling to acquire the principles of good practice in an effort to provide the best learning experience to help their students to achieve the learning goals (Darling-Hammond, Flook, Cook-Harvey, Barron, \& Osher, 2020). While teachers are one of the responsible personnel for designing and provision of high quality education, University and College tutors strive to make sure that teaching practice equips pre-service teachers with relevant and required teaching skills.

In Tanzanian context, TP duration for pre- service teacher education programs in universities is16 weeks. The time is short compared to some other countries like Netherlands and Australia which have 48 and 24 weeks for teaching practice respectively (Wang, Coleman, Coley, \& Phelps, 2003). During TP, there are interruptions like preparation week after being assigned specific lessons to teach, examination weeks and holiday weeks that reduce the time for actual classroom interaction as it was intended. In this case, pre-service teachers' space for applying the theoretical knowledge into the real classroom situation and to consolidate their professional learning is relatively short. In response to this gap, few studies have investigated whether the TP duration is sufficient to improve pre-service teachers' professional capacity and how the TP is conducted. The following studies for instance, investigated on TP effectiveness for creative and performing arts students (Mannathoko, 2013), attitude of students towards TP (Ikitde \& Ado, 2015) and challenges facing the pre-service teachers during TP (Scott, Gentry, \& Phillips, 2014). The studies did not focus on how the length of TP sessions contributes toward effectiveness of preservice teachers' competencies, which creates the study gap to be addressed by this study.

Due to the increasing need for teachers in primary and secondary schools, universities and colleges in Tanzania admit large numbers of students in various educational programs. To qualify being a teacher, a pre-service teacher should have a command of both the theoretical part of the teaching content and teaching methodologies together with practical competencies which can be realized through the teaching practice (Bernard, 2015; OECD, 2009).

While Universities and colleges strive to produce many qualified and competent teachers, two questions come: First, how does the TP contribute to development of pre-service teachers' pedagogical competences? Secondly, how does the TP help pre- service teachers to merge theories and practices to improve teaching practices? Bernard (2015) investigated the core qualities and competencies essential for a teacher to have good practices in and out of classroom and listed the following key areas: experience of different educational settings, effective classroom management strategies, knowledge and understanding of assessment strategies and knowledge of teaching resources. To acquire and develop the core qualities, pre-service teachers require undergoing the teaching practice which is aimed at making them better teachers. Preservice teachers are expected to manage classroom teaching and other activities by demonstrating mastery in time usage, subject matter, teaching methodologies, control of students' behaviors, personal qualities and the use of teaching resources during classroom presentation (Nzilano, 2013). Furthermore, there are various taxonomies of teacher competences taught to pre-service teachers. These include the subject matters and teaching methodologies applied in delivering lessons (Manasia et al., 2020). During teaching practice, pre-service teachers learn to understand problems as they occur in teaching practices and experience the real teaching process over which they are expected to develop their pedagogical skills and confidence.

However, one of the main problems in the teaching practice is the mismatch between theory and practice as these two areas seem to be not integrated in a satisfactory way (Hardman, 2009; Hardman \& Dachi, 2012). By comparing the Tanzanian universities which have 8 weeks of TP for the first year and 8 weeks for second year which brings a total of 16 weeks for the entire TP program with universities in other countries which have more weeks for the TP, Tanzanian universities seem to have shorter time spent on the TP (Wang et al., 2003). This raises doubts on the efficiency of the TP programs in developing pre-service teachers' pedagogical competencies through harmonization of theories and practical experience. Therefore this study mainly aimed at investigating the contribution of teaching practice on pre-service teachers' pedagogical competencies. In achieving this general objective, the following questions were addressed; -

1. How is the TP conducted to mentor preservice teachers?

2. What are pre-service teachers' perceptions on the contribution of TP? 
3. How does the TP develop pre-service teachers' pedagogical competencies?

\section{Related Literature and Studies}

This section presents review of different studies related to the importance, contribution of TP to develop pre-service teachers' pedagogical competencies and how TP is conducted.

\section{Importance of Teaching Practice}

Students must undergo TP, which is a necessary requirement for the attainment of their degrees at the end of their studies (Adeleke, Adesina, Salami \& Adebayo,2011). This is because provision of quality education is beyond the classroom learning process. It must involve perfect nurturing environment to prepare teachers who will be responsible in managing and directing the learning activities (OECD, 2009). Whereas the low morale and motivation in various education systems result in poor teachers' professional performance, hence poor students' performance (Egbo, 2011), preservice teachers must have prior understanding of the TP because they must understand the requirements for proper attainment of the bachelor degrees. Egbo (2011) also shows that through interacting with experienced teachers, pre-service teachers can shape their professional qualities that enhance improvement of pedagogical practices.

Adeleke et al. (2011) argue that TP can improve the attitude and opinion of pre-service teachers on aspects like lesson preparation and presentation skills and the general interest in teaching after familiarizing with the real working environment. This enables preservice teachers to make effective preparation for teaching with clear selection of content, teaching and learning materials and delivery methods.

Furthermore, Kiggundu and Nayimuli (2009) argue that teaching practice is an integral component of teacher training. It grants teachers experience in the actual teaching and learning environment. This means teachers get into practical situations when they are in their TP sessions, although there are some courses on teaching methodology in each teaching subject learned prior to teaching practice. But these courses provide only the theoretical part, thus denying teachers an opportunity to experience real challenges and setbacks that can only be experienced from the TP sessions. Kiggundu and Nayimuli (2009) further note that teaching practice can sometimes become a demoralizing and sometime frightening experience especially to first year students who practice teaching for the first time. They tend to have fear of facing students and sometimes fail to take the roles as real teachers. The TP experience, therefore, grant them practical exposure for them to be able to face and overcome similar situations at the beginning of their future career.

\section{Contribution of TP on Pedagogical Competencies}

Teaching practice offers an opportunity for preservice teachers to familiarize and act like professional teachers (Kiggundu \& Nayimuli, 2009; Komba \& Kira, 2013; Mannathoko, 2013). Teaching practice, according to Manasia et al. (2020), refers to a session where pre-service teachers translate professional knowledge into practice. This therefore gives pre-service teachers a room to experience teaching professionalism and act like teachers in the ways of communication, content mastery, preparation of teaching and learning materials and getting used with the teaching methods.

Nzilano (2013) argue that host teachers in schools have to mentor pre-service teachers through active support that will enable their career growth. They need to learn different skill from experienced teachers such as professional code of conduct and ethics. The interaction with mentors, students and the school environment is useful for pre-service teachers to understand their pedagogical strengths and weakness and improve. This gives pre-service teachers a room to acquire specific techniques, methods, strategies and experiences that helps to motivate them to build and consolidate their competences.

Pre-service teachers must therefore go for teaching practice so as to develop their teaching capacity. Meutia, Elyza and Yusnila (2018) cement that, TP is one of the learning environments where the preservice teachers experiment the acquired knowledge into real classroom practices. Hattie (2012) identifies components of effective teaching practices. These are; Teacher clarity- to provide learning goals and criteria for reaching them, classroom discussion - to engage students in the process of learning and observe their participation and Feedback -providing the success and failures of learners and making corrections. Furthermore, during $T P$, students are given chance to give feedback to their teachers. There is also formative assessment-which involves frequently and routinely 
assessing the achievement of specific units of study towards achieving the goals. Next are metacognitive strategies whereby students have the chance to monitor their works, direct their own learning and make some reflection as they progress. Competent teachers must have the ability to manage all these activities, which can be mastered gradually through practices and mentorship from experienced peers. That is why teaching practice is very central for developing pedagogical competencies to pre-service teachers.

\section{Models of Teaching Practice in Tanzania and other Countries}

In Tanzania, universities like the University of Dar es salaam, Mzumbe University, and Mwalimu Nyerere Memorial Academy have a homogeneous format of teaching practice in which students take eight weeks during first year break and eight weeks during second year break (MNMA, 2019; Mzumbe University, 2020; University of Dar es Salaam, 2019). Normally, TP is conducted during long holidays soon after the end of second semester between July and September. During the period of TP, pre-service teachers have to spend all the time in respective schools teaching subjects of their specialization while observing and learning from experienced teachers. Assessment by university lecturers is conducted once or twice depending on the policy of a specific university. For example, the University of Dar es salaam has the policy that requires at least two assessments per TP while Mzumbe University requires only a single assessment by university lecturers and one by head of host school. Single assessment is not adequate as it does not give preservice teachers a chance to work on the recommendations provided by supervising lecturers and have a second chance to teach and be assessed whether they have incorporated the comments for improvements.

There are universities that send students for TP after the end of first semester between February and May during first and second years. Students from these universities spend between five to seven weeks but the TP is conducted three times through the entire three year degree program (Myalla, 2014). For instance, Ruaha Catholic University conducts TP for seven weeks between March and April after finishing university examination of first semester (Ruaha Catholic University, 2017). The reason for this variation of TP period was that, many universities sent their students for TP in the same period resulting to over crowdedness of pre-service teachers in hosting schools. This situation leads to failure of TP candidates to fully engage in practicing their theoretical package in school and classroom environment due to the over crowdedness.

In South Africa, Kiggundu and Nayimuli (2009) show that, there are several model of teaching practice. These include- i) spending one day in every week in teaching at a certain school, ii) spending the whole semester in teaching practice and iii) block teaching practice and spending two to eight weeks in schools teaching after a university semester. For example, in Vaal University of Technology, students who pursue postgraduate program in education are required to spend 12 weeks on teaching practice. This is a one year program which awards students with a postgraduate certificate in education.

In Namibia, pre-service teachers have to participate in three phases of teaching practice during the four years of pursuing Bachelor's degree in education. In phase one and two, they have to spend three weeks in each phase at the schools of their choice. In the last teaching practice phase, pre-service teachers have to teach under the assistance of experienced teachers for a period of eight weeks and are assessed by host subject teachers (Ankonga, 2018). Yet still the eight weeks seems to be shorter for preservice teachers to merge theoretical skills with practical in real classroom environment (Scott, 2013).

According to Nakpodia (2011), in Nigeria the duration of teaching practice for pre-service teachers is eleven weeks at the end of second semester where students go to teach to the schools of their choice after being accepted by host schools. The assessment is conducted twice by the assessors from respective universities and one assessment is done by the principal of the host school. The average of the two assessments conducted is taken to be the final teaching practice score of the students. Yet the period of twelve weeks seems to be not enough for pre-service teachers to merge their theoretical knowledge and practical skills. However, during the semester they are taught a teaching practice course that orients and prepares them with classroom teaching sessions ready for field practice (Aglazor, 2017; Adegbola, 2019).

The TP duration in Botswana ranges from two to ten weeks (Mangope et al., 2018; Mannathoko, 2013). First year candidates spend two weeks only in making observation and writing a report, they are 
not engaged in classrooms teaching. Second year candidates conduct TP for ten weeks, engaging in classrooms teaching and writing a field report while third year students spend five weeks in doing similar activities. According to Mangope et al. (2018), many pre-service teachers believed that the TP duration is not enough to develop pedagogical competencies and some candidates experienced poor relationship with experienced teachers in host schools.

In the United States, the teaching practice varies from six weeks to a full semester. This varies from one state to another (Wang et al., 2003). During this time, pre-service teachers work as assistant teachers under experienced teachers while learning and observing teaching and learning activities. They are only allowed to teach in the presence or under the supervision of experienced teachers as they learn and observe. Wang et al. (2003) further report similar practice in other countries like England, the US, Netherlands, Japan, Hong Kong, Korea and Australia where teaching practice ranges from a minimum of 3 weeks in Japan to a maximum of 72 weeks in Netherland.

\section{Research Methodology}

This part presents research design, population and sampling, data analysis, validity and reliability and ethical issues as adopted by this study.

\section{Research Design}

The study employed a case study design that was conducted at Mzumbe University in Tanzania. The case study also used mixed method approach with qualitative as a predominant approach.

\section{Population and Sampling}

The population of the study was constituted by 345 first year and second year pre-service teachers studying Bachelor of Education at Mzumbe University. These pre-service teachers are part of three degree programs offered at the university which are Bachelor of Education in Commerce and Accountancy, Bachelor of Education in Languages and Management and Bachelor of Education in Economics and Mathematics.

A sample size of 81 pre-service teachers, which is equivalent to $23.5 \%$ of the population, who conducted their TP in secondary schools located in Mbeya, Morogoro, Dodoma and Kilimanjaro regions. The gender distribution of respondents was 47 (58\%) males and 34 (42\%) females. The age of respondents ranged from 18 to 41 years, and $44.4 \%$ were first years while $55.6 \%$ were second years.
Convenience sampling technique and purposive sampling technique were used to obtain sample of respondents to participate in the study through filling in the questionnaire. Convenience sampling technique was appropriate as researchers, who collected the data, visited schools in the four regions for the purpose of TP assessment. During these visits, pre-service teachers who were assessed were included in the sample as informants. A total of 81 respondents $(100 \%)$ filled in and returned the questionnaires. The prepared questionnaire had 36 items most of which being in a five point Likert scale type from 1 strongly disagrees to 5 strongly agree. Items 1-6 sought to determine personal information of respondents. Items 7-9 sought to establish how teaching practice was conducted in respondents' respective schools. Items $10-13$ sought to determine how TP candidates perceive the importance of TP. Items 14-19 sought to establish their perception on the contribution of TP on developing pedagogical competencies. Items 20-31 sought to examine how TP assessment was conducted, their satisfaction and challenges. Lastly items 32-36 demanded respondents to give suggestions on the areas of improvement regarding how TP is conducted.

Purposive sampling technique, on the other hand, was used to select respondents for in-depth interview. Leaders of pre-service teachers in each TP stations were purposively selected because of their position as representatives of others. Therefore from the sample of 81 pre-service teachers involved in the study, 18 respondents were purposively selected to participate in a semi structured in-depth interview. The guiding interview questions were three as follows: how is the TP conducted to mentor pre-service teachers? How pre-service teachers perceive the importance of TP? How the TP develop pre-service teachers' pedagogical competencies?

\section{Data Analysis}

The descriptive tool from SPSS version 20 software was used in analyzing the quantitative data from the questionnaires and presented results through frequencies and percentage. Interviews were recorded using a voice recorder app in a smart phone and then data were transcribed into texts. The transcriptions were coded and categorized according to study questions and few selected quotations were used to support the claims in the presentation sections. 


\section{Validity and Reliability}

In the study, validity and reliability were attentively considered throughout the research process. In reliability, the research procedure followed clear steps from preparing the proposal and presenting for peer review and discussion which refined the focus and ways of obtaining the data. Also after getting the data, the process of writing, reading and re-reading the transcript were done. The process also involved re-visiting of the respondents and conducting interviews on the same questions in a paraphrased way to compare their data.

\section{Ethical considerations}

Ethical considerations were observed to all participants. Before giving out the questionnaires, pre-service teachers were informed about the study that was being conducted and those who agreed filled in the questionnaires. The participants who agreed to participate were ensured that, the data collected or information provided would be used only for the study and not otherwise. Respondents' identities were hidden as those who filled questionnaires used numbers instead of names and those who participated in interviews were named respondent 1 to respondent 18 . Also they were given a freedom to withdraw anytime they would wish to and skip items they think was too sensitive to personal information.

\section{Findings and Discussion}

This section presents and analyses the information collected from respondents. Specifically, it deals with how TP is conducted in host schools, how it contributes to pre-service teacher pedagogical competencies and how pre-service teachers are satisfied with the TP process. In responding to specific objectives of the study, detailed analysis is presented below. The presented data was extracted and analyzed from the questionnaires filled by respondents as well as the interview information.

\section{How TP is conducted in Host Schools}

The study explored how TP is conducted in host schools with an intention to establish the contribution of teaching practice in the pre-service teachers' pedagogical competencies. All respondents (100\%) strongly agreed that TP is an important hands-on experience to equip them with necessary knowledge to understand the learning environment. On the question about getting cooperation from host schools, $91.2 \%$ of respondents indicated that the school management cooperated well with them. This indicates that host schools cooperated well with TP candidates, which is a prime factor for their improved pedagogical competencies. On the contrary, $8.8 \%$ indicated the cooperation was poor in the sense that TP preservice teachers were not well perceived by some of the teachers and students in host schools. This implies that those who were supported by host school teachers were properly mentored and gained necessary teaching skills and those who were not cooperated their skills were not raised for better teaching improvement.

Also, when asked about accessibility to teaching facilities and materials, $74 \%$ indicated that they were provided with necessary materials and facilities, $8.6 \%$ indicated that materials and facilities were not available while $17.3 \%$ were neutral. This indicates that materials and facilities are provided although some schools seem not to have necessary materials like syllabi, textbooks and other necessary facilities. In this situation pre-service teachers may not manage to build pedagogical capacity on issues like proper interpretation of curricula materials or effective delivery of their lessons.

On receiving the assistance from management of host institutions, $86.4 \%$ said there was active and positive cooperation from the host institutions while $13.6 \%$ said there was weak cooperation from the host institutions. One student, for instance said that, "I got maximum cooperation and assistance from the school, as they provide me with necessary materials, facilities and incentives like meals and housing" (Respondent 14, 2019).

The study further established that motivation and incentives are a problem to many schools due to the fact that about $50.6 \%$ of the respondents said there were no incentives to motivate them during TP while only $28.4 \%$ agreed to have received some incentives. Other respondents (21\%) were neutral. One student when interviewed said, "The school is nice, and I hope to come here next time. We have remedial classes where the schools paid 5,000 Tsh per hour, and I covered many hours since I teach mathematics...." (Respondent 5, 2019).

Most of the students were generally satisfied on how TP was conducted. The mean score of their response concerning satisfaction with TP assessment was 4.17. This implies that there is a high rate of satisfaction on assessment done during their teaching practice, although, the mode of 
assessment used by lecturers, number of assessment and students understanding of teaching practice had the mean score of 3.94, 3.67 and 3.95 respectively which denotes the 'neutral response.' This suggests that respondents neither agreed nor disagreed with particular statements in the questionnaire. Therefore, to raise the perception of respondents on the quality of $T P$, there is a need of reviewing the mode of assessment, duration of TP and number of assessment during teaching practice as suggested by Komba and Kira (2013) to help preservice teachers improve their teaching capacity through provision of feedback for improvements. This will identify how many times pre-service teachers should be assessed per TP. There is need to extend the TP duration similar to other countries to prepare competent and quality teachers.

The study further established that pre-service teachers faced some serious challenges when conducting their TP. While syllabi and textbooks are very important as they help pre-service teachers develop practical skills on interpreting curricular materials and presenting the lesson in the classroom, responses showed that $30.9 \%$ of preservice teachers said that instructional materials like syllabi and textbooks are inadequate compared to $28.4 \%$ who said they are adequate. Other preservice teachers, $40.8 \%$ were neutral. Some preservice teachers were in dilemma to evaluate the adequacy materials because they used online sources to compliment available hard copies of materials in school libraries. This might explain the high percentage of neutral response. Another challenge observed from pre-service teachers was inability to control the classes as well as poor ability to use English as the language of instruction, which is the recommended language for interaction in schools. These results indicate the inability in teaching preparations, limited mastery of the language of instruction and limited knowledge of teaching strategies (Nzilano, 2013). The likely reason for pre-service teachers to struggle pedagogically is weak training and practice. The weak aspects in managing and controlling the class during teaching and learning require proper training during preservice teaching sessions at respective universities. .

The study also established that there is no good mentor-novice relationships in helping pre-service teachers develop practical experience in teaching. Commenting on this, Vumilia and Semali (2017) suggest that experienced teachers should pass on the knowledge in these aspects to student teachers, which is not always the case as indicated by results of this study. Particularly, $41 \%$ of respondents indicated that they were not mentored by experienced teachers, $42 \%$ were neutral as they failed to exactly rate the assistance they were given while only 16.6 said they were well mentored. While TP is aimed at building teachers professional capacity through improving pedagogical competencies in a more practical way than through the theoretical component, mentoring novice teachers helps them to understand the professional practices in the field, hence making them competent in the teaching profession (Mgeni \& Anangisye, 2017). Therefore, pre-service teachers need close supervision and assessment from host teachers of the schools they are assigned to undergo the TP. Their performance should be measured in the way they teach in classrooms and how they manage overall classroom activities (Meutia et al., 2018). If pre-service teachers are not mentored by experienced field teachers, they will fail to develop practical skills hence will not be competent teachers after graduation. It is also important to note that pre-service teachers who lack mentorship from host school teachers may end up developing limited competencies compared to those who have been well mentored.

Cooperation and respect from students in host institution is another challenge that was indicated by respondents as only $39.3 \%$ of pre-service teachers said they had good relationship and respect and cooperated well with students in schools where they were teaching while $32.9 \%$ said they did not have the good relationship and cooperation. One pre-service teacher, for instance said, "They don't respect us because they regard us as temporary teachers, and when you are teaching advanced levels the situation is even worse as they say soon we are going to meet at the university..." (Respondent 18, 2019). This is a problem towards development of pre-service teachers' pedagogical competencies. When pre-service teachers are not respected, they tend to be de-motivated and as a result, they may end up treat students with excessive force, which can develop the hateful behavior towards the teaching profession and anxieties (Kiggundu \& Nayimuli, 2009).

\section{Importance of TP by Pre-service Teachers}

The study sought to examine students' understanding of TP and its importance in building their professional capacity. Majority of respondents (81.3\%) showed that they understood the TP in 
general and its importance in helping them to develop content and pedagogical competency. This suggests that several respondents (18.7\%) did not understand why they went for teaching practice. Records also indicate that there are others who left their TP stations immediately after assessment had taken place. This is an indication that such students valued grades rather than practical skills to improve their professional practices. The study also found out that $78.8 \%$ of pre-service teachers had positive attitude towards TP, while $15 \%$ and $6.2 \%$ of respondents were in 'neutral' and 'disagree' category respectively. Therefore, majority had positive attitude toward TP. Regardless of majority having positive attitude towards TP, $87.3 \%$ indicated a need to improve the TP orientation prior to commencing the actual TP. Orientation is very important since it gives pre-service teachers a clear picture of the school and environmental settings they are likely to face during their future career. This is proven by the fact that $84.8 \%$ of pre-service teachers who received TP orientation prior to departure to their fields agreed that the orientation was very helpful since it helped them predict and prepare for the situations they faced like students behaviors, reception and interaction with teachers from the host institutions.

\section{Contribution of TP on Pedagogical Competence}

In spite of a few challenges expressed by results of this study, most of respondents agreed that TP has a positive contribution toward enhancing the development of pedagogical competencies. Particularly, the response shows that they agreed that TP is very useful with the mean of 4.6. A good number of respondents (92.4\%) further agreed that TP contributes in consolidating mastery of the subject matter and improves pedagogical competencies for effective delivery of lessons. The experience led them to read and respond to questions raised by students in the classroom, hence making them master well the content of the subjects they taught before entering the classroom.

Furthermore, TP helps pre-service teachers to develop competencies in using multiple teaching methods and therefore be flexible in the classroom. This is supported by the fact that about $96 \%$ of respondents indicated that they developed practical skills of shifting to various teaching methods during the time of teaching practice. The ability to use varieties of teaching methods helps TP candidates with different abilities to learn and understand what they had been taught before going to the field for
TP. n harmony with what Aglazor (2017) suggests that TP provides a challenging and yet a rewarding experience of dealing with students in actual classroom setting and equips pre-service teachers with necessary professional competencies, one student said; -

I failed to use the teaching method I prepared before the lesson because of unpredictable mood of the class. You may plan to use discussion method and you find that your students are not cooperating; hence, you have to change the method (Respondent 1, 2019).

Furthermore, the choice and use of instructional materials, designing teaching aids appropriate for specific lessons and classroom skills were strengthened during TP. The study found that, 93.8\% of respondents showed they benefited and had improved their skills on how to design, choose and use instructional materials specifically for the lessons they had planned to teach. This is also supported by Vumilia and Semali (2017) who pointed out that student teachers would use the locally available materials to design teaching aids necessary for the lessons.

Another contribution respondents mentioned was classroom management and interaction skills. This is revealed by the fact that, $95 \%$ of them showed that they developed practical skills on how to manage students with different behaviors and how to manage time and their presentation. On the contrary, just a few respondents $(5 \%)$ indicated that TP did not contribute much in developing management skills due to the short length of the TP. They mentioned that in urban schools there are many TP candidates such that in some teaching subjects they only got one topic or a few periods to teach. One student, for instance, said,

It is very difficult to improve our teaching skills because we cannot get enough time to practice. In this school, there are more than 90 pre-service teachers from various universities. I am teaching Kiswahili in form three, but we are 5 teachers teaching the same class the same subject. As a result, I taught three lessons only... (Respondent 11, 2019).

From the results, students find it difficult to practice their skills because of overcrowded pre-service 
teachers in schools. This is because many universities send students to TP at the same time.

Generally the findings show that there is a need to review teaching practice curricula and design it to give adequate time for pre-service teachers to consolidate their teaching skills. This is due to the fact that some pre-service teachers understand the importance of having teaching practice but they see the duration is not sufficient.

\section{Conclusions and Recommendations}

This section presents conclusions of the study and then gives corresponding recommendations.

\section{Conclusions of the Study}

The study concludes that pre-service teachers benefited from TP regardless of a few shortcomings which call for improvement. Concerning how the TP is conducted, the relationship between pre-service teachers and mentors strengthened development of pedagogical competencies, although in some schools the bond was weak resulting to limited acquisition of pedagogical competencies. The duration of five to eight weeks is not adequately enough for pre-service teachers to merge theories and practice in a professional manner. In most cases, 8 weeks are reduced to less than 6 weeks due to examination weeks, mid-term breaks and preparation days. Pre-service teachers were less satisfied with the assessment mode used by lecturers of having only one assessment that did not give them a chance to correct the weaknesses observed and re-teach to determine the level of improvements. Teaching and learning materials were found inadequate, hence making it difficult to have thorough preparation for teaching.

Respondents understood the importance of TP in developing pedagogical competencies and had positive attitude towards it. Although some did not realize the importance of $T P$, they left the stations immediately after assessment. TP has helped preservice teachers to understand nature and behavior of learners and how to organize learning activities suitable for each specific level. TP is very important to pre-service teachers where they integrate theories into practice that enhance the development of pedagogical competencies. Preservice teachers learned effective methods of delivering lessons and managing learning process. They also acquired skills of using multiple teaching methods within the lesson. The TP strengthened the abilities to choose and use of instructional materials as well as designing appropriate teaching aids for specific lessons and classroom skills. Findings also revealed that some pre-service teachers said TP did not contribute much in developing management skills due to limited time and lacking of proper mentorship.

\section{Recommendations of the Study}

The study recommends that host institution should first and foremost regard pre-service teachers as learners; hence experienced teachers' professional support and mentorship are what builds pre-service teachers capacity in managing teaching and learning. To encourage mentorship, experienced subject teachers should work hand-in-hand with pre-service teachers to assist them and help them achieve maximum professional capacity through practice. Their supervision, correction, discussion, assistance, evaluation, general practice and guidance are what pre-service teachers seek for improved professional practices. Assessment should be done twice or more as suggested by Komba and Kira (2013) as this will help re-assessing and improving preservice teachers' practices after the first and subsequent feedbacks to determine the improvement and progress. When assessment is conducted once, it does not give room to see whether the comments or corrections have been taken into consideration or not.

Orientation is very important since it gives preservice teachers a clear picture of the school and environment setting they are likely to face. TP assessors in collaboration with heads of schools should follow up whether students left immediately after being assessed before the end of their session so that appropriate actions should be taken against such students. There is a need for change of the general TP policy on duration and timing, that the preparations week should not be part of TP duration and the TP should be conducted before or after holidays and breaks so that pre-service teachers will spend all weeks in teaching. This requires a close cooperation between the government, university managements and hosting schools in making sure duration is reviewed and spent effectively to foster development of preservice teacher's pedagogical competencies.

To foster mentorship support that will result to build pedagogical capacity, pre-service teachers should prepare lesson plans and scheme of work for all periods per week and then the headmaster and subject teachers should sign, stamp and recommend 
on those materials every week up to the end date. At the end, pre-service teachers should be required to submit those signed materials to their TP assessors at the university. Having weekly assessment of materials prepares and used in classroom with signatures and stamp of the head of school and subject teachers will help to ensure the effective mentorship of pre-service teachers based on the recommendations provided. Lastly, TP requires a close cooperation between the government, university managements and hosting schools in making sure that the duration is reviewed and spent effectively to foster development of preservice teacher's pedagogical competencies.

\section{References}

Adegbola, F. F. (2019). Teachers' pedagogical competence as determinants of students' attitude towards basic science in South West Nigeria. Educational Research and Reviews, 14(18), 655-660. https:// doi.org /10.5897/ERR2019.3761

Adeleke, M. A., Adesina, B. . A., Salami, M. O., \& Adebayo., J. A. (2011). Influence of Teaching Practice Exercise on Accidental Teacher Education Candidates at the Obafemi Awolowo University, Ile-Ife. Review of Higher Education in Africa, 3(1-14).

Aglazor, G. (2017). The role of teaching practice in teacher education programmes: designing framework for best practice. Global Journal of Educational Research, 16(2), 101. https://doi.org/10.4314/gjedr.v16i2.4

Ankonga, A. K. (2018). Teachers ' perceptions of pre -service teacher training in Namibia : A case of pre- and junior primary teachers teaching through mother tongue in multilingual classroom. University of Eastern Finland Tiedekunta.

Bernard, M. (2015). The good teacher: An investigation of the core competencies and attributes of an effective educator. University of Toronto.

Darling-Hammond, L., Flook, L., Cook-Harvey, C., Barron, B., \& Osher, D. (2020). Implications for educational practice of the science of learning and development. Applied
Developmental Science, 24(2), 97-140. https://doi.org/10.1080/10888691.2018.15 37791

Egbo, B. (2011). Teacher Capacity Building and Effective Teaching and Learning: A Seamless Connection. Mediterranean Journal of Social Sciences, 2(5), 11-17. https://doi.org/10.5901/mjss.2015.v6n4s3p 256.

Hardman, F. (2009). A review of teacher education in Tanzania and the potential for closer links between PRESET and INSET. Dar es Salaam.

Hardman, F., \& Dachi, H. (2012). Evaluation of School-Based INSET Pilot Programme. In Final Report. Retrieved from http://www.york.ac.uk/media/iee/documen ts/Final report Tanzania INSET pilot 2013.pdf\%0AAll Papers/H/Hardman and Dachi 2012 - Evaluation of School-Based INSET Pilot Programme.pdf

Hattie, J. (2012). Visable learning for teachers maximizing impact on learning. London, Routledge

Ikitde, G. A., \& Ado, I. B. (2015). Attitude of Students towards Teaching Practice Exercise in Nigerian University: A Case Study of University of Uyo, Uyo. Journal of Education and Practice, 6(25), 69-74.

Kiggundu, E., \& Nayimuli, S. (2009). Teaching practice: A make or break phase for student teachers. South African Journal of Education, 29(3), 345-358. https://doi.org/10.15700/saje.v29n3a129

Komba, S. C., \& Kira, E. S. (2013). The Effectiveness of Teaching Practice in Improving Student Teachers ' Teaching Skills in Tanzania. 4(1), 157-164.

Manasia, L., lanos, M. G., \& Chicioreanu, T. D. (2020). Pre-service teacher preparedness for fostering education for sustainable development: An empirical analysis of central dimensions of teaching readiness. 
Sustainability (Switzerland), 12(1), 4-6. https://doi.org/10.3390/SU12010166

Mangope, B., Otukile-Mongwaketse, M., Dinama, B., \& Kuyini, A. B. (2018). Teaching Practice Experiences in Inclusive Classrooms: The Voices of University of Botswana Special Education Student Teachers. International Journal of Whole Schooling, 14(1), 57-92.

Mannathoko, M. C. (2013). Does Teaching Practice Effectively Prepare Student-Teachers to Teach Creative and Performing Arts? The Case of Botswana. International Journal of Higher Education, 2(2), 115-121. https://doi.org/10.5430/ijhe.v2n2p115

Meutia, P. D., Elyza, F., \& Yusnila, Y. (2018). PreService Teachers' Performance Post Microteaching Class in Field Experience Program. Englisia Journal, 5(2), 102. https://doi.org/10.22373/ej.v5i2.2889

Mgeni, P. L., \& Anangisye, W. A. L. (2017). The Roles of Experienced Teachers in Inducting Novice Teachers in Tanzania. Huria Journal, 24(3), 126-149.

MNMA. (2019). The Mwalimu Nyerere Memorial Academy Prospectus 2019/2020. Dar es Salaam: The Mwalimu Nyerere Memorial Academy.

Myalla, P. P. (2014). Assessing the Impact of the Duration of Pre-Service Training on Teachers Work Performance and Teaching Competences in Tanzania: The Case of Nyamagana Municipality (The Open University of Tanzania). https://doi.org/10.16526/j.cnki.114762/tp.2014.11.051

Mzumbe University. (2020). Mzumbe University Prospectus 2019/2020. Mzumbe: Mzumbe University.

Nakpodia, E. D. (2011). Teacher and the student practice teaching programme in Nigerian educational system. International Journal of
Educational Administration and Policy Studies, 2(3), 33-39.

Nzilano, J. L. (2013). Pre-Service Teachers' Teaching Competencies: The Experience of Practising Teaching in Secondary Schools and Teacher Colleges. African Journal of Teacher Education, 3(1), 1-21. https://doi.org/10.1017/СВ0978110741532 4.004

OECD. (2009). Teaching Practices, Teachers' Beliefs and Attitudes. In Creating Effective Teaching and Learning Environments: First Results from TALIS (pp. 87-135). https://doi.org/10.1787/9789264068780-6en

Ruaha Catholic University. (2017). Ruaha Catholic University Prospectus 2017/2018. Iringa Municipality: Ruaha Catholic University.

Scott, A. (2013). Teaching Practice at the University of Namibia: Quo Vadis? Africa Education Review, 10(1), 149-158

Scott, L. A., Gentry, R., \& Phillips, M. (2014). Making preservice teachers better: Examining the impact of a practicum in a teacher preparation program. Educational Research and Reviews, 9(10), 294-301. https://doi.org/10.5897/err2014.1748

University of Dar es Salaam. (2019). University of Dar es Salaam Undergraduate Prospectus 2019 / 2020. Dar es Salaam: University of Dar es Salaam.

Vumilia, P. L., \& Semali., L. M. (2017). Ways To Improve "Btp Quality" and the Extent Teaching Practice Contributes To Teaching Effectiveness. International Journal of Advanced Research, 5(10), 1082-1131. https://doi.org/10.21474/ijar01/5629

Wang, A. H., Coleman, A. B., Coley, R. J., \& Phelps, R. P. (2003). Preparing Teachers Around the World. In policy Information Report. https://doi.org/10.1177/003172170308500 319. 